\section{A seven-year follow-up of discharged patients after out-of-hospital cardiac arrest with respect to ST-segment elevation myocardial infarction}

\author{
MILOSLAV PLESKOT • RADKA HAZUKOVA • PETR PARIZEK \\ EVA CERMAKOVA • ILJA TACHECI
}

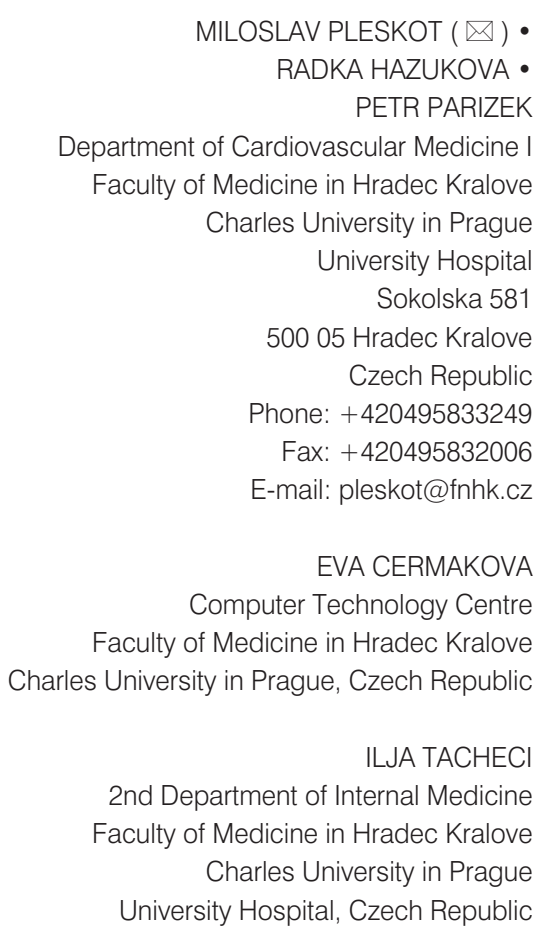

MILOSLAV PLESKOT $(\bowtie) \bullet$ RADKA HAZUKOVA • PETR PARIZEK

Department of Cardiovascular Medicine I Faculty of Medicine in Hradec Kralove Charles University in Prague University Hospital Sokolska 581 50005 Hradec Kralove Czech Republic

Phone: +420495833249 Fax: +420495832006 E-mail: pleskot@fnhk.cz

EVA CERMAKOVA Computer Technology Centre Faculty of Medicine in Hradec Kralove Charles University in Prague, Czech Republic

ILJA TACHECI 2nd Department of Internal Medicine Faculty of Medicine in Hradec Kralove Charles University in Prague University Hospital, Czech Republic

\begin{abstract}
Introduction. The aim of this multicentre prospective study was to describe the seven-year survival of patients, from the region of East Bohemia, after out-of-hospital cardiac arrest (OHCA), occurring between 2002 and 2004. The main focus of this study was on the survival of patients with ST-segment elevated myocardial infarction (STEMI).

Patients and Methods. A total 718 patients with OHCA were included in the study. Of these patients, 149 were admitted to hospital. The main cohort of our study consisted of 53 patients (41 men; median 59; average 58 \pm 13 ), who survived acute hospitalization. In these patients, STEMI was the main cause of OHCA in 15 cases (28\%), whereas without STEMI was found in 38 cases (72\%). Patients who survived hospitalization were periodically followed-up at six-monthly intervals.

Results. In the first follow-up year, 42 patients survived (79\% of 53 patients), in the third year 38 patients (72\%), in the fifth year 33 patients (62\%) and in the seventh year 31 patients (59\%). Ninety-four percent of patients were in good neurological condition after the seventh follow-up year. The whole period of seven years was survived by 12 (80\%) out of 15 patients with STEMI, and by 19 (50\%) out of 38 patients without STEMI. In patients who survived the seventh year after STEMI, direct percutaneous coronary intervention was performed in 11 cases.

Conclusions. Fifty-nine percent of patients discharged from hospital after OHCA survived until the seventh year. The highest rate of survival during this period was seen in patients with STEMI, i.e. in $80 \%$.
\end{abstract}

Key words: cardiac arrest, myocardial infarction, out-of-hospital cardiac arrest, sudden cardiac death, survivors, ventricular fibrillation

\section{Introduction}

Long-term prognosis of patients discharged from hospital after out-ofhospital cardiac arrest (OHCA) has been previously evaluated by various authors in the 1970s and 1980s. $(1,2)$ Few authors describe the survival of such patients in a time horizon longer than seven years. (3-6) In spite of the advances in medicine [revascularization of the myocardium, implantation of implantable cardioverter-defibrillators (ICD)], there is no unified opinion regarding the improvement of long term mortality after OHCA. $(6,7)$ A good prognosis is however expected in patients after ST-segment elevation myocardial infarction (STEMI). Comparison of survival in these patients with patients with STEMI without OHCA, and even with the normal population, shows no obvious differences in survival. (8-12) 
The aim of our study was to describe the seven-year survival in patients from the region of East Bohemia discharged after acute hospitalization for "primary cardiac" OHCA, mainly focusing on the survival of patients with STEMI.

\section{Patients and methods Study design}

This prospective multicentre (24 rescue service centres, 16 anaesthesiology and resuscitation departments, 19 internal medicine departments, and two cardiac -centres: Hradec Kralove and Pardubice) cohort study included patients recruited between 1 April, 2002 and 31 August, 2004 from the region of East Bohemia (an area of 11,244 km2 with 1,236,000 inhabitants) with OHCA of "primary cardiac" aetiology, who underwent professional cardiopulmonary resuscitation. (13) Exclusion criteria were: terminal phase of chronic diseases, OHCA in the presence of emergency medical system (EMS) staff and OHCA of non-cardiac aetiology (trauma, intoxication, drowning, and suicide including hanging). Primary cardiac aetiology of cardiac arrest was determined after the exclusion of clinically or autopsy confirmed non-cardiac causes.

This study was carried out in accordance with the Declaration of Helsinki and its realization was approved by the local ethics committee. Eligible patients gave written, informed consent.

\section{Patient group}

A total 718 patients (511 men and 207 women; aged 16-97 years; median 69; average $67 \pm 13$ ) with confirmed $\mathrm{OHCA}$ were reported to the rescue center dispatch. Professional cardiopulmonary resuscitation (CPR) was initiated in 560 patients with OHCA of „, primary cardiac" aetiology. Of these patients, 149 were admitted for hospitalization (with STEMI: 26 patients). Ninety-six patients died during hospitalization (64.4\%) (figure 1). The main cohort of our study consisted of 53 patients (41 men and 12 women, aged 25-79 years; median 59; average 58 \pm 13 ), who survived acute hospitalization. The duration of hospitalization in this main cohort was
$38 \pm 46$ days (median 22); longest hospitalization was 129 days.

In contrast to STEMI, identifying explicitly non-ST-segment elevation myocardial infarction from primary arrhythmia is difficult, if not impossible, thus authors divided the patient cohort into a subgroup with STEMI $(n=15)$ and a subgroup without STEMI (Others) $(n=38)$.

\section{Measurements}

Anamnestic data, prehospital data (including the initial rhythm on the electrocardiogram) and hospital care data (including principle diagnoses, presence of STEMI) were recorded by the EMS and hospital physicians on the questionnaires according to the Utstein protocol. (14) Therapeutic hypothermia was not used to treat OHCA in any of the included patients.

After discharge from hospital, data were provided by clinical specialists, mainly by cardiologists, general practitioners, and possibly directly by the patients. Patients who survived hospitalization were periodically followed-up at sixmonthly intervals for a period of at least seven years. Their medical condition was evaluated and their neurological status assessed based on cerebral performance categories (CPC) according to Glasgow-Pittsburgh Outcome Categorization. (15) Causes of death and the occurrence of sudden death were recorded.

\section{Statistical analysis}

Results are presented by absolute and relative counts, quantitative characteristics by mean \pm S.D. We used Fisher's exact test in contingency tables to compare characteristics of the survived and non-survived groups. A P value $<0.05$ was considered statistically significant. Statistical software NCSS 2007 and programme for calculating Fisher's exact test were used.

\section{Definition}

STEMI is defined as dynamic elevation of ST-segments on the electrocardiogram (at the $\mathrm{J}$ point with the cut-off points $\geq 0.2 \mathrm{mV}$ in $V_{1}$ through $V_{3}$ and $\geq 0.1 \mathrm{mV}$ in other leads) along with a typical rise (minimally three times greater than the upper limit of normal values), followed by a fall in biochemical mark- ers of myocardial necrosis [e.g. serum creatinine kinase and its MB fraction] and eventual evolution of a pathological $Q$ wave on the electrocardiogram (0.04 seconds or more in duration). For interpretation of biochemical markers of myocardial necrosis and STEMI after CPR (blood samples were evaluated for all patients), we included an evaluation of the urgent coronary angiogram prior to direct percutaneous coronary intervention $(\mathrm{PCl})$ and myocardial wall kinetics (ultrasound).

Sudden cardiac death is defined as unexpected total circulatory arrest within one hour from-onset of symptoms or without any warning.

\section{Results}

Basic prehospital and hospitalization characteristics of patients after OHCA who survived acute hospitalization $(n=53)$ and the first seven years of follow-up $(n=31)$, are provided in table 1. In comparing both groups, we demonstrated a statistically significant higher seven-year survival in patients who received CPR by health care professionals of $\leq 15$ min duration $P<0.001$ ), who underwent non-surgical (total: $P=0.021$; direct: $P=0.0497$ ) or surgical revascularization $(P=0.035)$ and in patients without evidence of post anoxic encephalopathy $(P=0.0101)$. During several years of follow-up after OHCA there were 31 patients $(58.5 \%$ of 53 patients) who survived the seventh year (figure 1). The highest annual death rate (11 patients; $50 \%$ of 22 deceased patients) occurred before the end of the first year.

\section{STEMI}

In 15 patients discharged from hospital, STEMI was diagnosed on admission to hospital (the initial rhythm was always ventricular fibrillation), i.e. $28.3 \%$ of 53 . In figure 2 the seven-year survival of patients with STEMI and without STEMI (Others) is compared. A statistically significant difference in survival between the two subgroups was demonstrated after the first $(P=0.0228)$ and third year $(P=0.0411)$. In patients who survived the seventh year after STEMI, direct PCl was performed in 11 cases (91.7\%). 
Table 1. Characteristics of patients after out-of-hospital cardiac arrest, who survived 1) hospitalization, and 2) the seventh year of follow-up.

\begin{tabular}{llll} 
Discharged alive & Alive at 7 years & $\begin{array}{l}\text { Non-alive } \\
\text { at } 7 \text { years } \\
(n=22 ; 100 \%)\end{array}$ & $\begin{array}{l}\text { Statistical } \\
\text { significance }(P)\end{array}$ \\
$(n=53 ; 100 \%)$ & $(n=31 ; 100 \%)$ & $(n=0)$ & \\
\hline
\end{tabular}

Baseline and prehospital characteristics

\begin{tabular}{|c|c|c|c|c|}
\hline $\begin{array}{l}\text { Age (years) } \\
\text { Median } \\
\text { Range } \\
\text { Mean } \pm S D\end{array}$ & $\begin{array}{l}59 \\
25-79 \\
58 \pm 13\end{array}$ & $\begin{array}{l}54 \\
25-79 \\
55 \pm 13\end{array}$ & $\begin{array}{l}63 \\
38-80 \\
62 \pm 12\end{array}$ & \\
\hline Men - no. (\%) & $40(76)$ & $24(77)$ & $16(73)$ & 0.753 \\
\hline $\begin{array}{l}\text { Initial cardiac rhythm - no. (\%) } \\
\text { Ventricular fibrillation } \\
\text { Ventricular tachycardia } \\
\text { Asystole } \\
\text { Third-degree atrioventricular block }\end{array}$ & $\begin{array}{l}43(81) \\
1(2) \\
7(13) \\
2(4)\end{array}$ & $\begin{array}{l}28(90) \\
0(0) \\
2(7) \\
1(3)\end{array}$ & $\begin{array}{l}15(68) \\
1(5) \\
5(23) \\
1(5)\end{array}$ & 0.102 \\
\hline $\begin{array}{l}\text { Location - no. (\%) } \\
\text { Home } \\
\text { Public place (out of home) }\end{array}$ & $\begin{array}{l}20(38) \\
33(62)\end{array}$ & $\begin{array}{l}9(29) \\
22(71)\end{array}$ & $\begin{array}{l}11(50) \\
11(50)\end{array}$ & 0.156 \\
\hline $\begin{array}{l}\text { Arrest witnessed - no. (\%) } \\
\text { Bystander CPR- no. (\%) }\end{array}$ & $\begin{array}{l}48(91) \\
26(49)\end{array}$ & $\begin{array}{l}28(90) \\
14(45)\end{array}$ & $\begin{array}{l}20(91) \\
12(55)\end{array}$ & $\begin{array}{l}1 \\
0.583\end{array}$ \\
\hline $\begin{array}{l}\text { Arrival time (min) } \\
\text { (call - ambulance arrival) - no. (\%) } \\
\leq 5 \mathrm{~min} \\
>5 \mathrm{~min}\end{array}$ & $\begin{array}{l}25(47) \\
28(53)\end{array}$ & $\begin{array}{l}15(48) \\
16(52)\end{array}$ & $\begin{array}{l}10(46) \\
12(55)\end{array}$ & 1 \\
\hline $\begin{array}{l}\text { Length of CPR by } \\
\text { health care professionals }- \text { no. (\%) } \\
0-15 \mathrm{~min} \\
16-30 \mathrm{~min} \\
\geq 31 \mathrm{~min}\end{array}$ & $\begin{array}{l}26(49) \\
16(30) \\
11(21)\end{array}$ & $\begin{array}{l}23(74) \\
5(16) \\
3(10)\end{array}$ & $\begin{array}{l}3(14) \\
11(50) \\
8(36)\end{array}$ & $<0.001$ \\
\hline $\begin{array}{l}\text { Hospital characteristics } \\
\text { Glasgow coma scale at admission } \\
- \text { no. (\%) } \\
3 \\
4-5 \\
\geq 6\end{array}$ & $\begin{array}{l}35(66) \\
8(15) \\
10(19)\end{array}$ & $\begin{array}{l}20(65) \\
4(13) \\
7(23)\end{array}$ & $\begin{array}{l}15(68) \\
4(18) \\
3(14)\end{array}$ & 0.773 \\
\hline $\begin{array}{l}\text { Cardiogenic shock - no. (\%) } \\
\text { Postanoxic encephalopathy } \\
\text { - no. (\%) } \\
\text { LVEF } \leq 35 \% \text { (ECHO) - no. (\%) }\end{array}$ & $\begin{array}{l}19(36) \\
20(38) \\
20(38)\end{array}$ & $\begin{array}{l}8(26) \\
7(23) \\
12(39)\end{array}$ & $\begin{array}{l}11(50) \\
13(59) \\
8(36)\end{array}$ & $\begin{array}{l}0.088 \\
0.0101 \\
1\end{array}$ \\
\hline $\begin{array}{l}\text { Revascularization - no. (\%) } \\
\text { PCI } \\
\text { - Total } \\
\text { - Direct } \\
\text { CABG }\end{array}$ & $\begin{array}{l}20(38) \\
13(25) \\
6(11)\end{array}$ & $\begin{array}{l}16(52) \\
11(36) \\
6(19)\end{array}$ & $\begin{array}{l}4(18) \\
2(9) \\
0(0)\end{array}$ & $\begin{array}{l}0.021 \\
0.0497 \\
0.035\end{array}$ \\
\hline ICD - no. (\%) & $14(26)$ & $10(32)$ & $4(18)$ & 0.348 \\
\hline $\begin{array}{l}\text { Main diagnosis - no. (\%) } \\
\text { IHD without acute myocardial infarction } \\
\text { IHD, STEMI - no. (\%) } \\
\text { Dilated cardiomyopathy } \\
\text { Aortic stenosis } \\
\text { Others }\end{array}$ & $\begin{array}{l}27(51) \\
15(28) \\
3(6) \\
1(2) \\
7(13)\end{array}$ & $\begin{array}{l}15(48) \\
12(39) \\
1(3) \\
0(0) \\
3(10)\end{array}$ & $\begin{array}{l}12(55) \\
3(14) \\
2(9) \\
1(5) \\
4(18)\end{array}$ & 0.111 \\
\hline
\end{tabular}

CABG, Coronary Artery Bypass Graft; CPR, Cardio-Pulmonary Resuscitation; ECHO, Echocardiography; ICD, Implantable CardioverterDefibrillator; IHD, ischemic heart disease; LVEF, Left ventricular ejection fraction; PCI, Percutaneous Coronary Intervention; STEMI, ST-segment Elevation Myocardial Infarction; P value, Fisher's exact test - the comparison Alive subgroups at 7 years $(n=31)$ with Non-alive subgroups at 7 years $(n=22)$. 
Cerebral performance category According to CPC categories, 42 patients (79.3\% from 53 patients) were in good neurological condition (CPC $-1,2)$ at the time of discharge from hospital. The relative percentage of patients with a CPC of 1,2 , was above 92\% during the seven-year follow-up period, in comparison with the numbers of patients surviving a particular year, i.e. first year $92.9 \%$, third year $97.4 \%$, fifth year $93.9 \%$ and seventh year $93.6 \%$ (table 2).

\section{Diagnosis}

Ischemic heart disease was the most frequent principle diagnosis in patients discharged from hospital (42 of 53 persons, i.e. $79.3 \%$ ), as well as in patients who survived for seven years (27 of 31 persons, i.e. $87.1 \%$ ) (table 1). Table 3 presents the causes of death at the seven-year follow-up after discharge from hospital. Sudden cardiac death occurred in 11 people in total (2 autopsied: 1 - acute myocardial infarction, 1 - ischemic heart disease without acute myocardial infarction), 4 of whom had implanted ICDs. In the storage dump of these ICDs no ventricular tachycardia events were recorded.

\section{Discussion}

There are only a few studies, mainly conducted in the last ten years, which have prospectively followed (for more than seven years) patients after OHCA, who had a physician present during CPR. (4) It is very problematic or even impossible to precisely and responsibly compare the results of several years' observation of patients after previous OHCA. These observations occur in various geographic areas and over various time periods, with variably developed and organised emergency rescue and medical systems. Therefore, we

Table 2. Glasgow - Pittsburgh Outcome Categorization (CPC) of brain injury in follow-up in patients who survived hospitalization for out-of-hospital cardiac arrest.

\section{CPC (\%)}

\begin{tabular}{llllll} 
Surviving & Discharged alive & $\mathbf{1}$ year & $\mathbf{3}$ years & $\mathbf{5}$ years & $\mathbf{7}$ years \\
\hline Total & $53(100)$ & $42(100)$ & $38(100)$ & $33(100)$ & $31(100)$ \\
$\mathbf{1}$ (Good cerebral performance) & $36(68)$ & $34(81)$ & $33(87)$ & $27(82)$ & $27(87)$ \\
$\mathbf{2}$ (Moderate cerebral disability) & $6(11)$ & $5(12)$ & $4(11)$ & $4(12)$ & $2(7)$ \\
$\mathbf{3}$ (Severe cerebral disability) & $4(8)$ & $1(2)$ & $1(3)$ & $2(6)$ & $2(7)$ \\
$\mathbf{4}$ (Coma/vegetative state) & $7(13)$ & $2(5)$ & $0(0)$ & $0(0)$ & $0(0)$ \\
\hline
\end{tabular}

CPC, cerebral performance categories (Source: 15).

Table 3. Causes of death in patients discharged from hospitalization after out-of-hospital cardiac arrest $(n=53)$ : a seven-year follow-up.

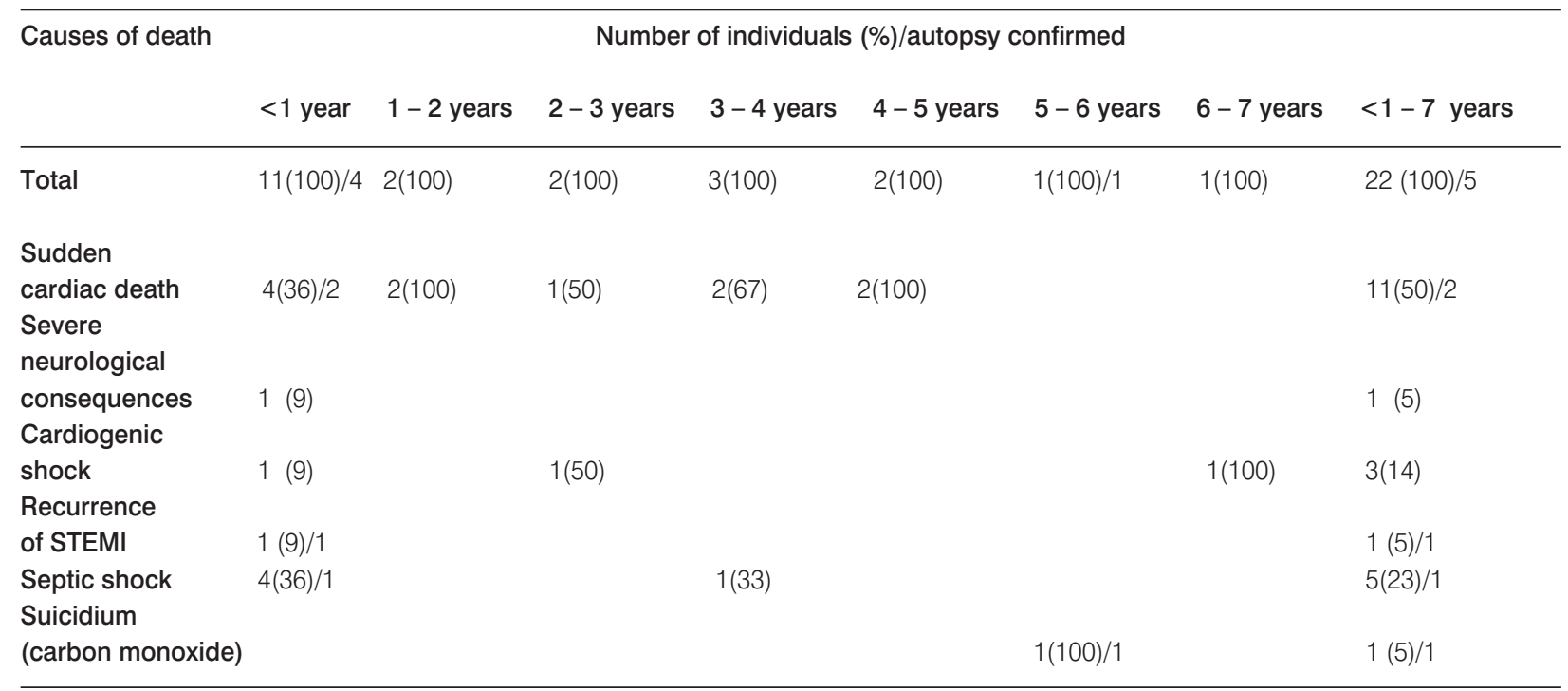

STEMI, ST-segment Elevation Myocardial Infarction. 


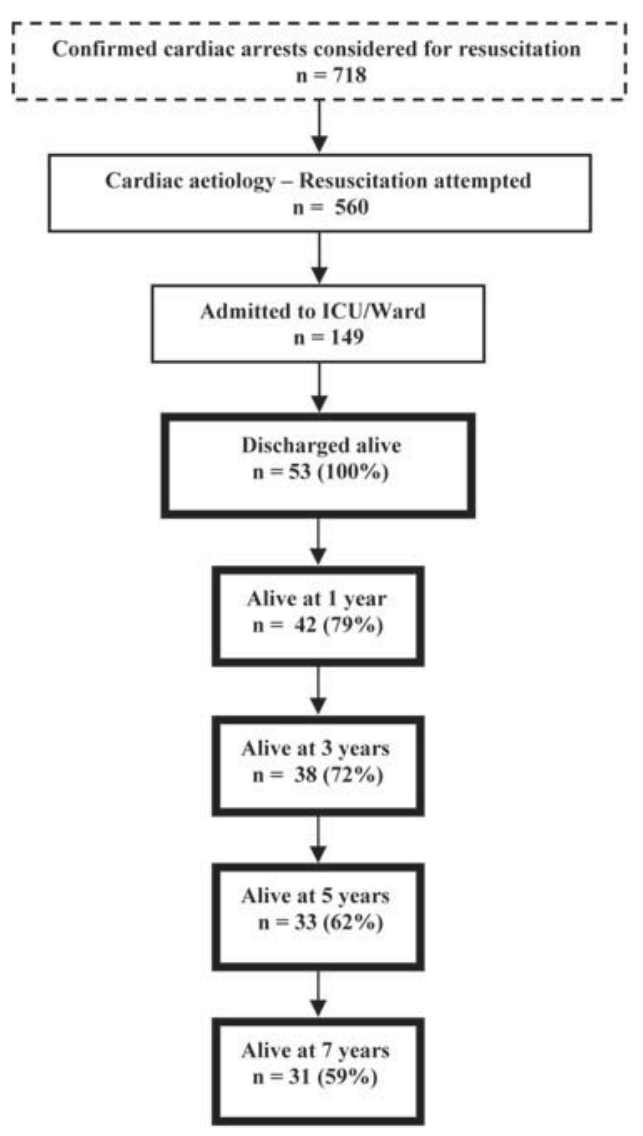

ICU, Intensive Care Unit.

Figure 1. Long-term survival of discharged patients with out-of-hospital cardiac arrest.

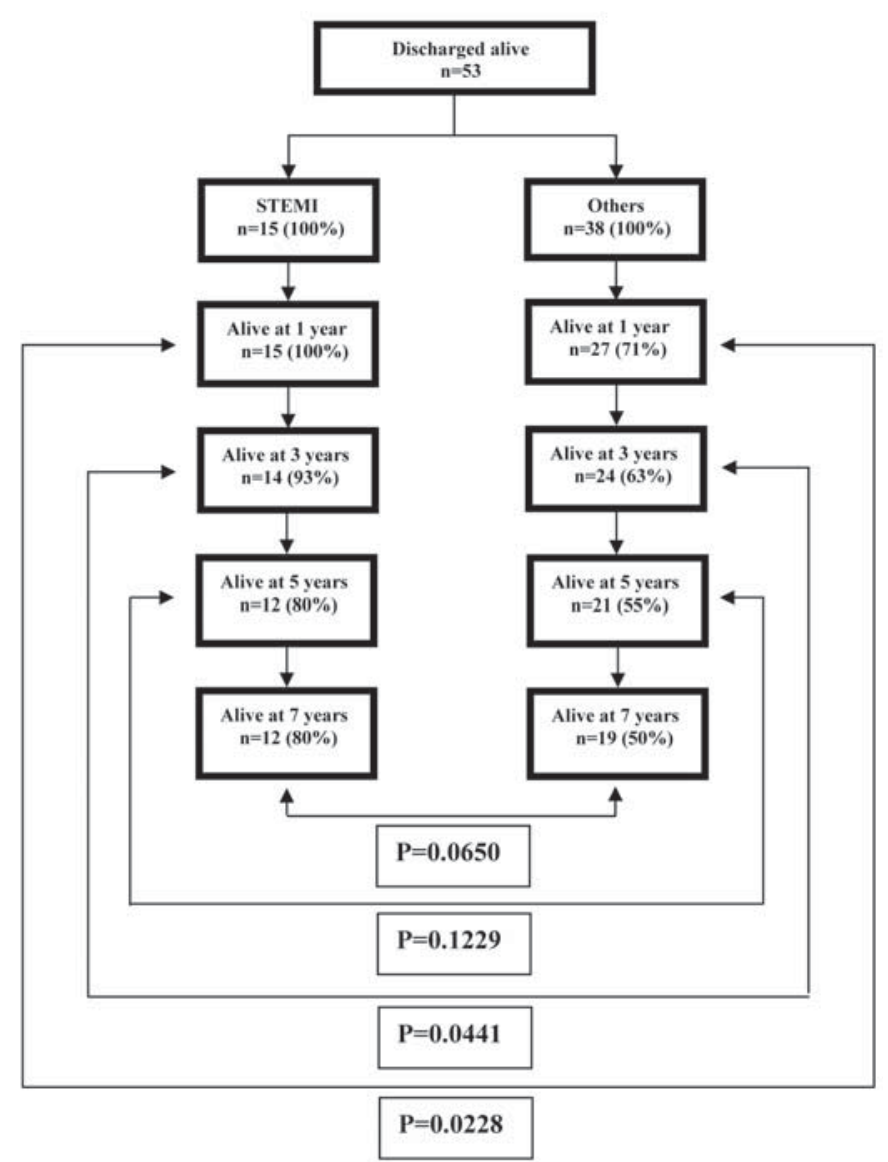

$P$ value, Fisher's exact test in contingency tables.

Figure 2. Survival of discharged patients after out-of-hospital cardiac arrest by ST-segment elevation myocardial infarction. consider it important, for the accuracy of clinical status of the patient, to evaluate the physician's long-term contact with the patient from the institution of CPR in the field to outpatient follow-up. Geographically, long-term studies include localities mainly in the United States of America and Europe (Denmark, Sweden, Norway, Estonia, the Netherlands, Scotland and Northern Ireland) (3-5,9,11,16-19). Data for our study were obtained from the region of East Bohemia in the Czech Republic. This locality included urban areas with a population of 100,000 inhabitants (Hradec Králové, Pardubice), as well as mountain regions (Krkonoše, Orlicky Mountains).

In our study we focused on the prospective evaluation of the seven-year survival in 53 patients, from discharge after OHCA of "primary cardiac" aetiology, between 2002 to 2004. In comparison with the reference literature, we demonstrated that the initial numbers of patients sampled ranged from 48 to 95 patients, $(4,11,16,19,20)$ and 139 to 680 patients. $(1,2,5,7,17,21-23)$ Most of these studies are however retrospective in nature with data obtained from central registers.

In our file, $79 \%$ of patients survived in the first year, $72 \%$ of patients in the third year, and $62 \%$ in the fifth year regardless of the initial cardiac rhythm. Data from other authors on survival in the first year range between 76 to $88 \%$, $(3-5,17,19,22)$ in the third year between 67 to $81 \%(4,5,17,22,23)$ and in the fifth year between 41 to $77 \%$. $(4,5,7,22,23)$ In our study, $59 \%$ of patients survived seven years after OHCA. Survival past 7 years has been reported by Kuilman (7 year survival: $73 \%$ ) (5) and Holler (10 year survival: $46 \%$ ). (4) The highest mortality (in our cohort $21 \%$ of 53 patients) is usually reported in the first year of follow-up. (21) It is obvious that longterm survival in patients after OHCA has not improved, when comparing previously published data, despite the improvement in medical care. (7) The long-term prognosis of patients discharged from hospital is mainly influenced by diagnostic and therapeutic measures undertaken during acute hospitalization and during subsequent long-term follow-up. $(2,3,11,17,24)$ 
Based on our prehospital factors, mortality after the seventh year of follow-up is reduced if the duration of professional CPR is less than 15 min. Based on hospital factors, it is the absence of post anoxic encephalopathy, and the performance of non-surgical or surgical revascularization of the myocardium that improves survival.

Different opinions can be found regarding the relationship between acute myocardial infarction and malignant tachyarrhythmia during OHCA on long-term survival. $(3,4,11,17,22,25)$ A good prognosis has been reported in patients who undergo emergency revascularization procedures. According to Bendz and Lettieri, the mortality of patients discharged from hospital with STEMI, after OHCA, is not significantly different from patients with STEMI but without an OHCA. $(9,12)$ In our study, patients with ventricular fibrillation during STEMI $(n=15)$, who were predominantly treated with direct $\mathrm{PCl}$ (in $87 \%$ ), had a survival rate of
$100 \%$ in the first year, $93 \%$ in the third year, and $80 \%$ in the fifth and seventh year. Survival in the first and third year was significantly different from the survival of patients without evidence of STEMI.

The relative percentage of patients discharged after acute hospitalization for PCA in good neurological condition (CPC - 1,2) was $79 \%$ in our cohort; in another cohort it was 74\%. (21) The high percentage of CPC of 1,2 in surviving persons during follow-up over several years (in our study above 92\%) mainly results from the deaths of patients with severe cerebral disability $(\mathrm{CPC}-3)$ or a coma/vegetative state $(\mathrm{CPC}-4)$ before the end of the first year after PCA. (21) Six percent of patients suffer from signs of dementia in the 6th month of followup according to Holler. (4)

\section{Limitations}

The main limitation of our study is the low number of patients in the principle cohort, which affected the statisti- cal analyses. Other imperfections of the study are the lack a control group for evaluating survival in the common population, as well as the low number of autopsies performed. Limitations, from the point of view of comparing survival with newer cohorts, include the lack of diagnostic and therapeutic procedures that have come into use since the beginning of our study in 2002 - 2004. This mainly concerns therapeutic hypothermia, the ICD implantations and selective coronarographies.

\section{Conclusions}

Of the 53 patients discharged from hospital after "primary cardiac" OHCA, 31 patients (59\%) in our study survived seven years, of which $94 \%$ were in good neurological condition (CPC 1,2). The highest rate of survival, for the same period, was demonstrated in patients with simultaneous evidence of STEMI, i.e. in $80 \%$ of 15 patients. The highest annual death rate occurred before the end of the first year.

\section{ACKNOWLEDGEMENTS}

We want to thank the personnel of the EMS, anaesthesiology and resuscitation departments, internal medical departments, clinical specialists- mainly cardiologists and general practitioners- of the region of East Bohemia. Without their co-operation this study never could have been performed.

\section{REFERENCES}

1. Cobb LA, Baum RS, Alvarez H 3rd, Schaffer WA. Resuscitation from out-of-hospital ventricular fibrillation: 4 years follow-up. Circulation 1975;52(6 Suppl):III223-35

2. Eisenberg MS, Bergner L, Hallstrom A. Survivors of out-of-hospital cardiac arrest: morbidity and long-term survival. Am J Emerg Med 1984;2:189-92

3. Dickey W, MacKenzie G, Adgey AA. Long-term survival after resuscitation from ventricular fibrillation occurring before hospital admission. Q J Med 1991:80:729-37.

4. Holler NG, Mantoni T, Nielsen SL, Lippert F, Rasmussen LS. Long-term survival after out-of-hospital cardiac arrest. Resuscitation $2007 ; 75: 23-8$.

5. Kuilman M, Bleeker JK, Hartman JA, Simoons ML. Long-term survival after out-of-hospital cardiac arrest: an 8-year follow-up. Resuscitation 1999;41:25-31

6. Rea TD, Crouthamel M, Eisenberg MS, Becker LJ, Lima AR. Temporal patterns in long-term survival after resuscitation from out-of-hospital cardiac arrest. Circulation 2003;108:1196-201.

7. Engdahl J, Bång A, Lindqvist J, Herlitz J. Time trends in long-term mortality after out-of-hospital cardiac arrest, 1980 to 1998 , and predictors for death. Am Heart J 2003;145:826-33. 
8. Allen LA, O'Donnell CJ, Camargo CA Jr, Giugliano RP, Lloyd-Jones DM. Comparison of long-term mortality across the spectrum of acute coronary syndromes. Am Heart J 2006;151:1065-71.

9. Bendz B, Eritsland J, Nakstad AR, Brekke M, Kløw NE, Steen PA, et al. Long-term prognosis after out-of-hospital cardiac arrest and primary percutaneous coronary intervention. Resuscitation 2004;63:49-53.

10. Bunch TJ, White RD, Gersh BJ, Meverden RA, Hodge DO, Ballman KV, et al. Long-term outcomes of out-of-hospital cardiac arrest after successful early defibrillation. N Engl J Med 2003;348:2626-33.

11. Engdahl J, Bång A, Karlson BW, Lindqvist J, Sjölin M, Herlitz J. Long-term mortality among patients discharged alive after out-of-hospital cardiac arrest does not differ markedly compared with that of myocardial infarct patiens without out-of-hospital cardiac arrest. Eur J Emerg Med 2001;8:253-61.

12. Lettieri C, Savonitto S, De Servi S, Guagliumi G, Belli G, Repetto A, et al. LombardIMA Study Group. Emergency percutaneous coronary intervention in patients with ST-elevation myocardial infarction complicated by out-of-hospital cardiac arrest: early and medium-term outcome. Am Heart J 2009;157:569-75.

13. Pleskot M, Babu A, Kajzr J, Kvasnicka J, Stritecky J, Cermakova E, et al. Characteristics and short-term survival of individuals with out-ofhospital cardiac arrests in the East Bohemian region. Resuscitation 2006;68:209-20.

14. Jacobs I, Nadkarni V, Bahr J, Berg RA, Billi JE, Bossaert L, et al. International Liason Committee on Resuscitation. Cardiac arrest and Cardiopulmonary resuscitation outcome reports: update and simplification of the Utstein templates for resuscitation registries. A statement for healthcare professionals from a task force of the international liaison committee on resuscitation (American Heart Association, European Resuscitation Council, Australian Resuscitation Council, New Zealand Resuscitation Council, Heart and Stroke Foundation of Canada, InterAmerican Heart Foundation, Resuscitation Council of Southern Africa). Resuscitation 2004;63:233-49.

15. Brain Resuscitation Clinical Trial I Study Group. A randomized clinical study of cardiopulmonary- cerebral resuscitation: design, methods, and patient characteristics. Am J Emerg Med 1986;4:72-86.

16. Bunch TJ, White RD, Bruce GK, Hammill SC, Gersh BJ, Shen WK, et al. Prediction of short- and long-term outcomes by electrocardiography in survivors of out-of-hospital cardiac arrest. Resuscitation 2004;63:137-43.

17. Cobbe SM, Dalziel K, Ford I, Marsden AK. Survival of 1476 patients initially resuscitated from out of hospital cardiac arrest. BMJ 1996;312:1633-7.

18. Pell JP, Corstorphine M, McConnachie A, Walker NL, Caldwell JC, Marsden AK, et al. Post-discharge survival following pre-hospital cardiopulmonary arrest due to cardiac aetiology: temporal trends and impact of changes in clinical management. Eur Heart J 2006;27:406-12.

19. Reinhard V, Pärna K, Lang K, Pisarev H, Sipria A, Starkopf J. Long-term outcome of bystander-witnessed out-of-hospital cardiac arrest in Estonia from 1999 to 2002. Resuscitation 2009;80:73-8.

20. Myerburg RJ, Kessler KM, Estes D, Conde CA, Luceri RM, Zaman L, et al. Long-term survival after prehospital cardiac arrest: analysis of outcome dutiny an 8 year study. Circulation 1984;70:538-46.

21. Graves JR, Herlitz J, Bång A, Axelsson A, Ekström L, Holmberg M, et al. Survivors of out of hospital cardiac arrest: their prognosis, longevity and functional status. Resuscitation 1997;35:117-21.

22. Kimman GP, Ivens EM, Hartman JA, Hart HN, Simoons ML. Long-term survival after successful out-of-hospital resuscitation. Resuscitation 1994;28:227-32.

23. Tresch DD, Keelan MH Jr, Siegel R, Troup PJ, Bonchek LI, Olinger GN, et al. Long-term survival after prehospital sudden cardiac death. Am Heart J 1984;108:1-5.

24. Bunch TJ, Kottke TE, Lopez-Jimenez F, Mahapatra S, Elesber AA, White RD. A comparative analysis of short- and long-term outcomes after ventricular fibrillation out-of-hospital cardiac arrest in patients with ischemic and nonischemic heart disease. Am J Cardiol 2006;98:857-60.

25. Baum RS, Alvarez H 3rd, Cobb LA. Survival after resuscitation from out-of-hospital ventricular fibrillation. Circulation 1974;50:1231-5. 